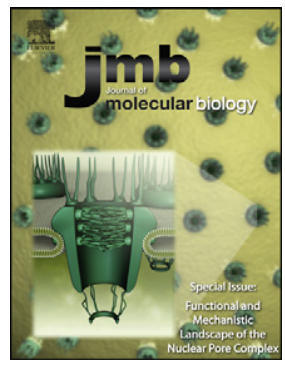

\title{
Structural and Calorimetric Studies Demonstrate that Xeroderma Pigmentosum Type G (XPG) Can Be Imported to the Nucleus by a Classical Nuclear Import Pathway via a Monopartite NLS Sequence
}

\author{
Andrea C. de Barros ${ }^{1}$, Agnes A.S. Takeda ${ }^{1}$, Thiago R. Dreyer ${ }^{1}$, \\ Adrian Velazquez-Campoy ${ }^{2,3,4}$, Bostjan Kobe ${ }^{5}$ and Marcos R.M. Fontes ${ }^{1}$
}

1 - Departamento de Física e Biofísica, Instituto de Biociências, Universidade Estadual Paulista, Botucatu, SP, 18618-970 Brazil 2 - Institute of Biocomputation and Physics of Complex Systems, Joint-Unit Institute of Physical Chemistry "Rocasolano"-Consejo Superior de Investigaciones Científicas-Institute of Biocomputation and Physics of Complex Systems, University of Zaragoza, Zaragoza, 50018, Spain 3 - Department of Biochemistry and Molecular and Cell Biology, University of Zaragoza, Zaragoza, 50018, Spain

4 - Fundacion Agencia Aragonesa para la Investigación y el Desarrollo, Government of Aragon, Zaragoza, 50018, Spain

5 - School of Chemistry and Molecular Biosciences, Institute for Molecular Bioscience and Australian Infectious Diseases Research Centre, University of Queensland, Brisbane, Queensland 4072, Australia

Correspondence to Marcos R.M. Fontes: Departamento de Física e Biofísica, Instituto de Biociências, Universidade Estadual Paulista, Botucatu, SP, 18618-970,Brazil. fontes@ibb.unesp.br

http://dx.doi.org/10.1016/j.jmb.2016.01.019

Edited by: M. Guss

\begin{abstract}
Xeroderma pigmentosum type G (XPG) proteins are involved in DNA lesion recognition and promotion of nucleotide excision repair. Specific mutations in these proteins may lead to Cockayne syndrome, in which the patients may display severe developmental retardation and neurological abnormalities. No structural information is available for their spacer region or the C-terminal domain, which are important, respectively, for specific nucleotide excision repair activity and substrate specificity, as well as nuclear translocation. Immunofluorescence studies suggested two specific regions of the XPG C-terminus as potential bipartite nuclear localization sequences, which would be responsible for its translocation to the nucleus by the classical nuclear import pathway mediated by the importin- $\alpha$ (Impa). Thus, in order to test these hypotheses and gain insight into the structural basis for the nuclear import process for the XPG protein, we solved the crystal structures of complexes formed by the Impa and peptides corresponding to both putative nuclear localization signal (NLS) sequences (XPG1 and XPG2) and performed isothermal titration calorimetry assays to determine their binding affinities. Structural experiments confirm the binding of both NLS peptides to Impa but, unexpectedly, they bind to the receptor as monopartite NLSs. The isothermal titration calorimetry assays demonstrated that XPG1 and XPG2 peptides bind to two separate binding sites, but with high affinity to the major NLS-binding site of the Impa, resembling classical monopartite SV40 TAg NLS. The results lead to insights about what distinguishes monopartite and bipartite NLSs, as well as the differential roles of XPG1 and XPG2 NLSs in the nuclear localization of XPG.
\end{abstract}

(C) 2016 Elsevier Ltd. All rights reserved.

\section{Introduction}

Xeroderma pigmentosum proteins are involved in DNA lesion recognition and promotion of nucleotide excision repair (NER) [1]. Xeroderma pigmentosum proteins are classified in seven groups (XPA through XPG) associated with distinct steps of NER [2]. They also interact with proteins critical for genome organization and maintenance not involved in NER [3]. Mutations in xeroderma pigmentosum proteins are often related to different cancer types and are responsible for the disease xeroderma pigmentosum, an autosomal recessive skin disorder characterized by extreme UV sensitivity and an increased incidence of sunlight-induced skin cancers. Xeroderma pigmentosum type $\mathrm{G}$ (XPG) proteins (also known as excision 


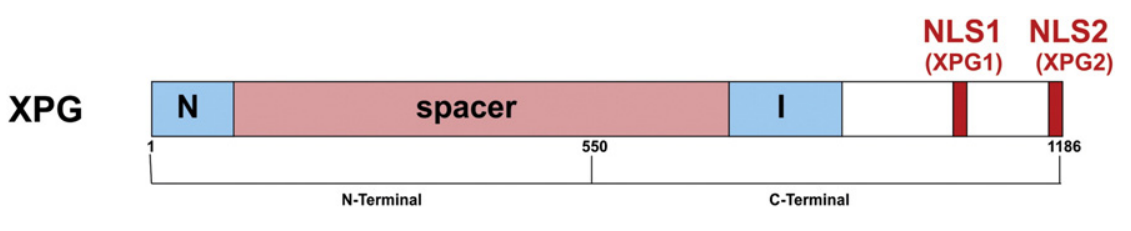

NLS1 (XPG1) 1057 - KRGITNTLEESSSLKRKRL - 1074

NLS2 (XPG2) 1169 - GKKRRKLRRARGRKRKT - 1186

Fig. 1. Schematic diagram of the XPG domains and its putative NLS regions. Nucleases domains (N and I) are shown in blue, spacer region is in salmon and the two putative NLS regions (termed here as XPG1 and XPG2) are in red. Both putative NLS sequences [12] are also shown.

repair cross-complementation group 5) belong to the FEN-1 family of structure-specific nucleases and play an essential role in both NER pathways, transcription-coupled repair and global genome repair [1,4-8]. Mutations in XPG proteins may also lead to the Cockayne syndrome, associated with severe developmental retardation, dwarfism and neurological abnormalities $[9,10]$.

XPG proteins are large proteins (134 kDa) that have two nuclease domains similar to FEN-1 proteins but also contain a spacer region of approximately 600 amino acids between them, as well as a C-terminal region of approximately 300 amino acids [11] (Fig. 1). Despite that both XPG and FEN-1 contain nuclease domains, they present different activities; FEN-1 is primarily involved in DNA replication, while XPG is involved in DNA repair by NER, which is a function mainly attributed to the spacer region. Domain-swap studies between FEN-1 and XPG indicated specific regions of XPG involved in its NER activity and substrate specificity [11]. Immunofluorescence studies suggested two regions of the XPG C-terminal domain as potential nuclear localization signals (NLSs) [12] responsible for the translocation of the XPG to the nucleus. Structural data of the XPG are scarce; structures are available for its nuclease domains [13], but no structural information is available for the spacer region or for its $\mathrm{C}$-terminal domain.

Thus, in order to learn more about structurefunction relationships in XPG, it is essential to understand how its transport to the cell nucleus occurs and how it is regulated. Several proteins whose functions are associated to DNA replication (such as FEN-1) or DNA repair [14-17] are imported to the cell nuclei by the so-called classical nuclear import pathway. This is the best characterized and probably the most used protein import mechanism to the cell nucleus, which involves the binding of the cargo protein via nuclear localization sequence (NLS) recognized by the importin- $\alpha$ protein (Impa). Impa is an adaptor that binds to the carrier importin- $\beta$
(Imp $\beta$ ), forming the cargo protein-Impa-Imp $\beta$ complex. This complex is transported to the nucleus through interaction between Imp $\beta$ and proteins from the nuclear pore complex, known as nucleoporins [18]. Classical nuclear localization sequences (cNLSs) are the best-characterized targeting signals that link the cargo proteins to the Impa import receptor. They are formed by one or two basic clusters of amino acid residues, termed monopartite or bipartite NLSs, respectively, and have the following consensus sequences: $K(K / R) X(K / R)$ for monopartite cNLS and $K R X_{10-12} K(K / R) X(K / R)$ for bipartite cNLS (where $X$ corresponds to any residue and residues in boldface indicate critical residues) $[19,20]$. Impa receptor is able to bind these positively charged clusters at two different sites, called as minor or major binding sites [21]; monopartite sequences usually bind to the major binding site, and bipartite sequences bind at both sites.

Previous studies with peptides from the XPG $\mathrm{C}$-terminal region, using in situ immunofluorescence localization of transiently expressed $\beta$-galactosidase fusion proteins, uncovered two putative bipartite cNLSs [12] (Fig. 1). The authors of this study also hypothesized that one of these peptides may contain a putative nuclear retention signal (NRS) [22]. Thus, in order to test these hypotheses and gain insights into the structural basis for nuclear import for the XPG protein, we solved the crystal structures of the complexes formed by Impa and both putative NLSs sequences (termed here as Impa-XPG1 and Impa-XPG2). Furthermore, we also performed isothermal titration calorimetry (ITC) assays aiming to quantify the binding process between XPG NLS peptides and Impa. Structural experiments confirmed the binding of both NLS peptides to Impa, but surprisingly, they bound to the receptor as classical monopartite NLS peptides. ITC assays demonstrated that XPG1 and XPG2 peptides bind with high affinity to the major NLS-binding site of the Impa, similarly to the classical monopartite SV40 TAg NLS [23,24]. 
Table 1. X-ray data collection and refinement statistics Impa-XPG1 NLS Impa-XPG2 NLS

Diffraction data statistics

Unit cell $(\AA)$

\begin{tabular}{|c|c|c|}
\hline a & 78.6 & 78.5 \\
\hline$b$ & 89.5 & 90.8 \\
\hline$c$ & 99.8 & 101.0 \\
\hline Space group & \multicolumn{2}{|c|}{$P 2_{1} 2_{1} 2_{1}$} \\
\hline Resolution $(\AA)$ & $\begin{array}{c}40.0-2.0 \\
(2.07-2.0)^{\mathrm{a}}\end{array}$ & $\begin{array}{c}40.0-2.8 \\
(2.88-2.8)^{a}\end{array}$ \\
\hline Unique reflections & 47,986 & 33,617 \\
\hline Multiplicity & $4.3(4.0)^{\mathrm{a}}$ & $4.4(4.3)^{\mathrm{a}}$ \\
\hline Completeness (\%) & $99.4(99.1)^{\mathrm{a}}$ & $99.3(100)^{a}$ \\
\hline$R_{\text {merge }}{ }^{\mathrm{b}}(\%)$ & $12.9(64.1)^{\mathrm{a}}$ & $13.8(94.9)^{\mathrm{a}}$ \\
\hline Average $I / \sigma(I)$ & $6.3(2.4)^{a}$ & $6.9(1.5)^{a}$ \\
\hline \multicolumn{3}{|l|}{ Refinement statistics } \\
\hline Resolution $(\AA)$ & $\begin{array}{c}40.0-2.0 \\
(2.07-2.0)^{\mathrm{a}}\end{array}$ & $\begin{array}{c}40.0-2.80 \\
(2.88-2.80)^{a}\end{array}$ \\
\hline Number of reflections & 47,972 & 17,937 \\
\hline$R_{\text {cryst }}(\%)^{\mathrm{c}}$ & 17.1 & 17.1 \\
\hline$R_{\text {free }}(\%)^{d}$ & 19.2 & 21.7 \\
\hline \multicolumn{3}{|c|}{ Number of non-hydrogen atoms } \\
\hline Protein & 3250 & 3163 \\
\hline Peptide & 139 & 107 \\
\hline Solvent & 189 & 02 \\
\hline Mean $B$-factor $\left(\AA^{2}\right)$ & 46.5 & 77.0 \\
\hline Coordinate error $(\AA)^{\mathrm{e}}$ & 0.20 & 0.33 \\
\hline \multicolumn{3}{|l|}{ RMSD from ideal values $^{e}$} \\
\hline Bond lengths $(\AA)$ & 0.007 & 0.010 \\
\hline Bond angles $\left({ }^{\circ}\right)$ & 1.08 & 1.28 \\
\hline \multicolumn{3}{|l|}{ Ramachandran plot (\%) } \\
\hline $\begin{array}{l}\text { Residues in most favored } \\
\text { (disallowed) regions }^{\dagger}\end{array}$ & $99.7(0.23)$ & $95.3(1.40)$ \\
\hline
\end{tabular}

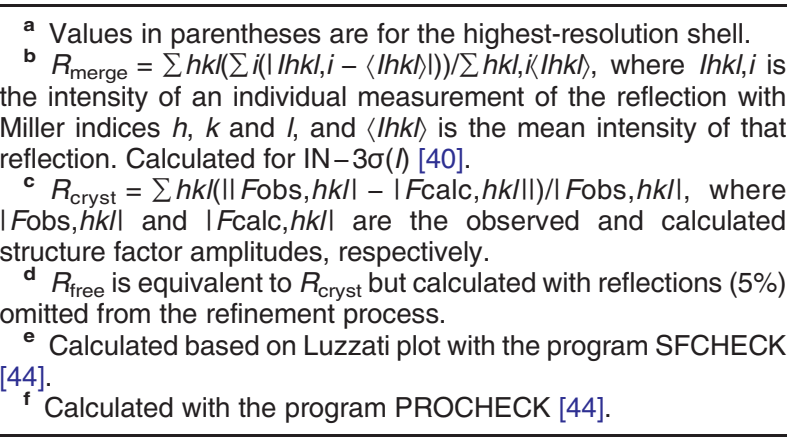

\section{Results}

\section{Structure of Impa complexed with NLS peptides corresponding to different regions of the XPG protein}

Peptides corresponding to two different regions of the human XPG (XPG1 NLS and XPG2 NLS) were co-crystallized with $\mathrm{N}$-terminally truncated mouse Impa lacking residues 1-69 (Impa $\Delta \mathrm{IBB})$; the truncated residues are responsible for its autoinhibition [25]. Mouse Impa is a suitable model for the human protein as the residues interacting with NLS peptides are strictly conserved, as previously observed $[17,21,26]$. The co-crystals were grown under similar conditions to other mouse Impa-NLS peptides complexes and were isomorphous to them $[17,26,27]$. The structures were refined at 2.0 and $2.8 \AA$ resolutions, respectively, for Impa-XPG1 NLS and Impa-XPG2 NLS complexes (Table 1). Electron density maps based on the Impa model clearly showed electron density corresponding to fragments of the peptides in two different regions of the protein, known as major and minor binding sites (Figs. 2 and 3). These NLS-binding sites are located in a concave groove on the surface of Impa formed by the $\mathrm{H} 3$ helices. The major binding site is located at armadillo (ARM) repeats $2-4$, while the minor site is located at ARM repeats $6-8$. The Impa structures in both XPG1 and XPG2 NLS complexes are essentially identical with that of full-length Impa and other complexes with monopartite NLS-like peptides reported previously. The root-mean-square deviations (RMSDs) of $\mathrm{C}^{\alpha}$ atoms of Impa residues 72-496 are 0.24 and $0.30 \AA$ between the full-length Impa (PDB ID 1IAL) and the Impa-XPG1 or Impa-XPG2 complexes, respectively. The equivalent superpositions between Impa-SV40 TAg NLS (PDB ID 1EJL) and the Impa-XPG1 NLS or Impa-XPG2 NLS complexes yield RMSD values of 0.25 and $0.32 \AA ̊$, respectively.

\section{Binding of XPG1 NLS to Impa structure}

The crystal structure of Impa-XPG1 NLS complex showed the presence of two peptides bound to Impa. Although the peptide contains two clusters of positively charged amino acids, it appears to interact with its NLS-binding sites resembling a monopartite NLS sequence [21]. The peptides bind with their main chains positioned in antiparallel configuration when compared to the direction of the ARM repeats and the sequences could be identified unambiguously in the electron density maps. At the major NLS-binding site, the electron density is present for seven peptide residues $\left({ }^{1069}\right.$ LKRKRLS $\left.^{1075}\right)$ with an average $B$-factor of $53.8 \AA^{2}$ (the average $B$-factor for entire Impa is $52.4 \AA^{2}$ ) (Fig. 2). The residues bound to the core of major NLS-binding site (residues 1070-1074; positions P1-P5) have lower average $B$-factors $\left(49.6 \AA^{2}\right)$ compared to Impa. The residues K1071 and R1074 (positions P2 and P5) have the lowest $B$-factors (41.6 and $46.5 \AA^{2}$, respectively) and the largest number of interactions between NLS side chains and side chains of conserved residues of Impa (Fig. 4). At the minor site, the electron density is present for six peptide residues ( ${ }^{1069}$ LKRKRL $^{1074}$ ) with an average $B$-factor of $61.8 \AA^{2}$ (Fig. 2). The residues bound in the core of the minor NLS-binding site (residues 1071-1074; positions P1'-P4') have higher average $B$-factors $\left(58.2 \AA^{2}\right.$ ) compared to the entire protein. The buried surface area between the protein and the peptide corresponds to $775.0 \AA^{2}$ at the major site and $570.3 \AA^{2}$ at the minor site. The superposition of $C^{\alpha}$ atoms between XPG1 and SV40 


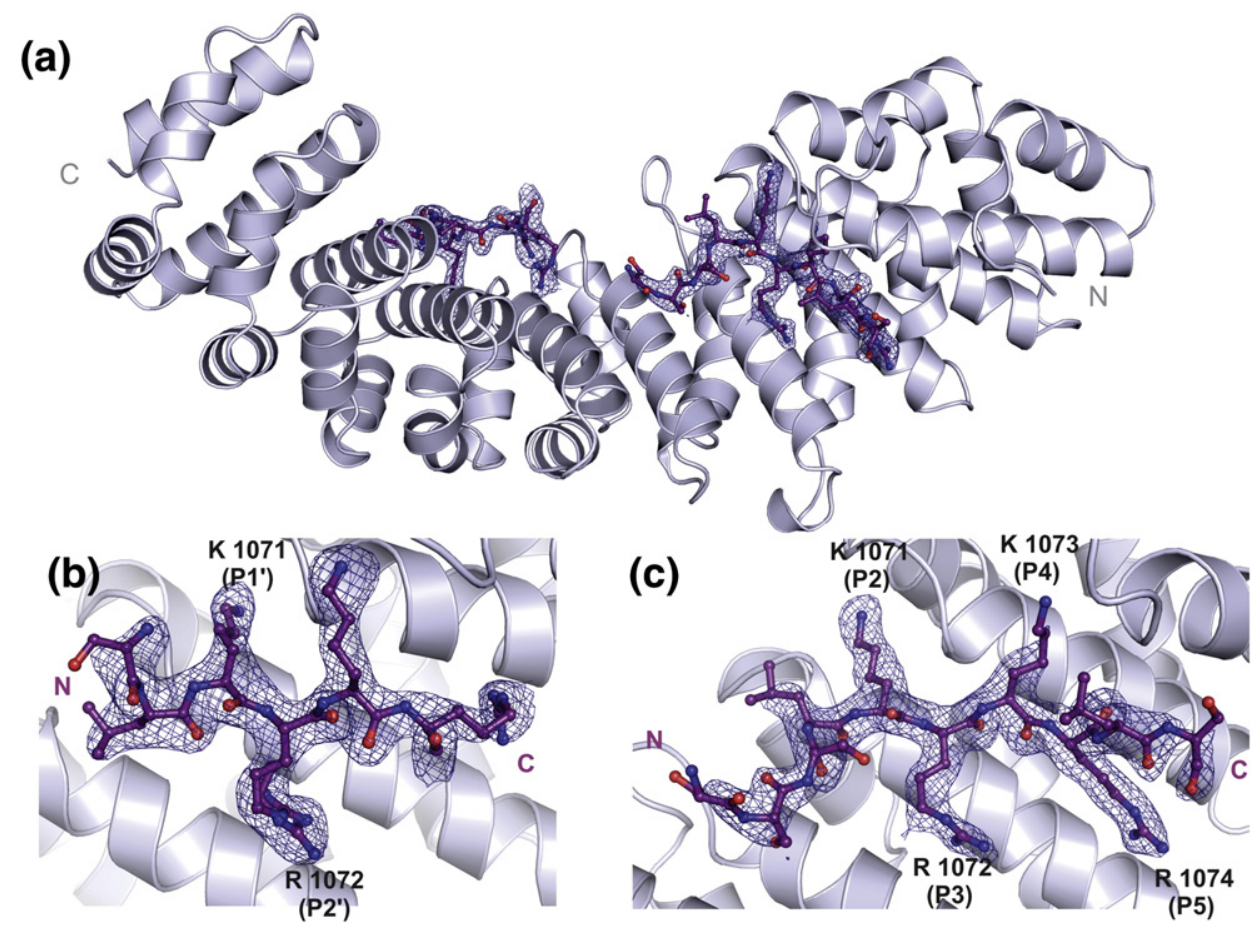

Fig. 2. Crystal structure of the Impa-XPG1 NLS complex. (a) Overall structure of the Impa-XPG1 NLS complex. Impa is shown as a ribbon diagram and XPG1 NLS peptide at major and minor binding sites are shown in stick representation. (b) Electron density omit map of the XPG1 NLS peptide at the minor site region of Impa (contoured at 2 S.D.). The main peptide residues are labeled in their corresponding binding position. (c) As in (b), but for major site region of the Impa.

TAg NLS peptides yields an RMSD of $0.11 \AA$ for the major binding site and $0.12 \AA$ for the minor binding site (Fig. 5).

\section{Binding of XPG2 NLS to Impa structure}

The crystal structure of Impa-XPG2 NLS complex showed the presence of two peptides bound to Impa, again interacting with its NLS-binding sites resembling a monopartite NLS sequence [21]. In this case, some ambiguity was observed in the electron density for few positions of the minor binding site, which could be related to multiple binding conformation of the peptide and to the moderated resolution of the data. At the major NLS-binding site, the electron density is present for eight peptide residues $\left({ }^{1168} \mathrm{GKKRRKLR}^{1176}\right)$ with an average $B$-factor of $84.0 \AA^{2}$ (the average $B$-factor for Impa is $74.4 \AA^{2}$ ) (Fig. 3). The residues bound in the core of the major NLS-binding site (residues 1169-1073; positions $\mathrm{P} 1-\mathrm{P} 5)$ have lower average $B$-factors $\left(69.9 \AA^{2}\right)$ compared to Impa. The residues K1070 and R1073 (positions P2 and P5) have the lowest $B$-factors (64.9 and $67.8 \AA^{2}$, respectively) and the largest number of interactions between NLS side chains and side chains of conserved residues of Impa (Fig. 4). At the minor site, the electron density is present for five peptide residues $\left({ }^{1182}{ }^{R K R K T}{ }^{1186}\right)$ with an average $B$-factor of $80.9 \AA^{2}$ (Fig. 3). The residues bound in the core of the minor NLS-binding site (residues 1183-1186; positions $\mathrm{P} 1^{\prime}-\mathrm{P} 4^{\prime}$ ) have higher average $B$-factors $\left(80.3 \AA^{2}\right)$ compared to the entire protein. The buried surface area between the protein and the peptide corresponds to $666.7 \AA^{2}$ at the major site and $530.4 \AA^{2}$ at the minor site. The superposition of $C^{\alpha}$ atoms between XPG2 and SV40 TAg NLS peptides yields an RMSD of $0.09 \AA$ for the major binding site and $0.53 \AA$ for the minor binding site (Fig. 5).

\section{Comparison between the binding of XPG1, XPG2 and other NLSs to Impa}

The comparison between XPG1, XPG2, SV40 TAg and other NLS peptides displays high conservation of the peptides conformation in major site region but higher deviation for the minor biding site, particularly for the XPG2 peptide (Fig. 5). The alignments of XPG1, XPG2, SV40 TAg and other monopartite NLSs are shown in Table 2. It can be observed that XPG1 and XPG2 NLSs bind according to the established consensus sequence in the major binding site. Furthermore, XPG1 and XPG2 NLSs have KR residues, respectively, at positions $\mathrm{P}^{\prime}$ and $\mathrm{P} 2^{\prime}$ of the minor binding site; this is the pattern adopted for the majority of monopartite NLS 

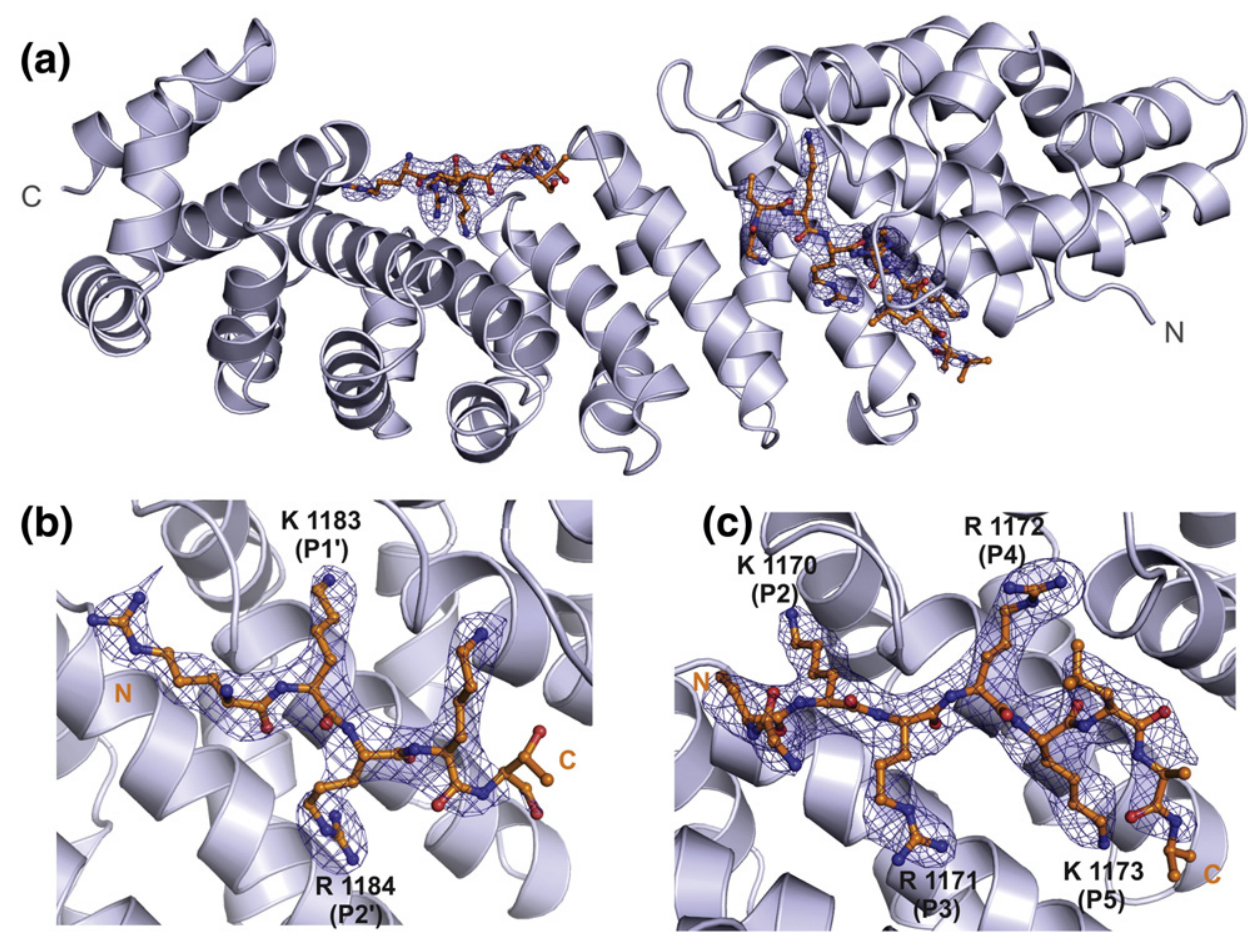

Fig. 3. Crystal structure of the Impa-XPG2> NLS complex. (a) Overall structure of the Impa-XPG2 NLS complex. Impa is shown as a ribbon diagram and XPG2 NLS peptide at major and minor binding sites are shown in stick representation. (b) Electron density omit map of the XPG2 NLS peptide at the minor site region of Impa (contoured at 2 S.D.). The main peptide residues are labeled in their corresponding binding position. (c) As in (b), but for major site region of Impa.

peptides, which bind to both major and minor binding sites (SV40 TAg NLS is an exception where alternative registers were observed [21]).

\section{Calorimetric assays of XPG1 and XPG2 NLSs and Impa}

Representative thermograms of calorimetric titrations for both complexes are shown in Fig. 6. Binding isotherms for XPG1 and XPG2 NLS peptides and Impa receptor were best fitted with a non-linear regression model of two binding sites. Thermodynamic parameters determined in the data analysis are presented in Table 3 . The dissociation constants $\left(K_{\mathrm{d}}\right)$ of XPG1 and XPG2 NLSs for major binding site of Impa are in the same order of magnitude; however, for the minor binding site, the binding affinity for XPG2 NLS to the receptor is very low $(140 \pm 20 \mu \mathrm{M})$. Thermodynamic parameters $(\Delta H$ and $\Delta S)$ are very similar for the major NLS-binding site for both XPG1 and XPG2 NLSs, with favorable enthalpic and entropic contributions to the binding Gibbs energy. However, the interaction in the minor NLS-binding site differs significantly not only in affinity but also in the partition of the Gibbs energy into binding enthalpy and entropy.

\section{Discussion}

\section{XPG1 and XPG2 are classical monopartite NLSs}

The crystal structures of Impa-XPG1 NLS and Impa-XPG2 NLS complexes are very similar to other monopartite NLS-Impa complexes for Impa from Mus musculus $[17,21,26]$ and from other organisms [23,28-30]. Impa structures have conserved concave surfaces, formed by $\alpha$-helices where the NLS-binding sites are localized. Conserved Asn residues form hydrogen bonds with the cNLS backbone, and Trp side chains form an array of binding cavities with negative residues located at the end of these grooves. The disruption of this Trp-Asn array in the ARM repeats 5 and 6 is also a conserved feature in all Impa structures, creating a region where the so-called linker region for bipartite NLSs is accommodated. The presence of an Arg residue in the ARM repeat 6 and a Tyr residue in the ARM repeat 5 can increase the affinity of the NLS linker region to Impa $[17,31]$.

Structural comparisons of XPG1 and XPG2 bound to Impa, with the cNLS monopartite peptides, such as SV40 TAg, Ku70 and Ku80 NLSs bound to Impa, 
(a)

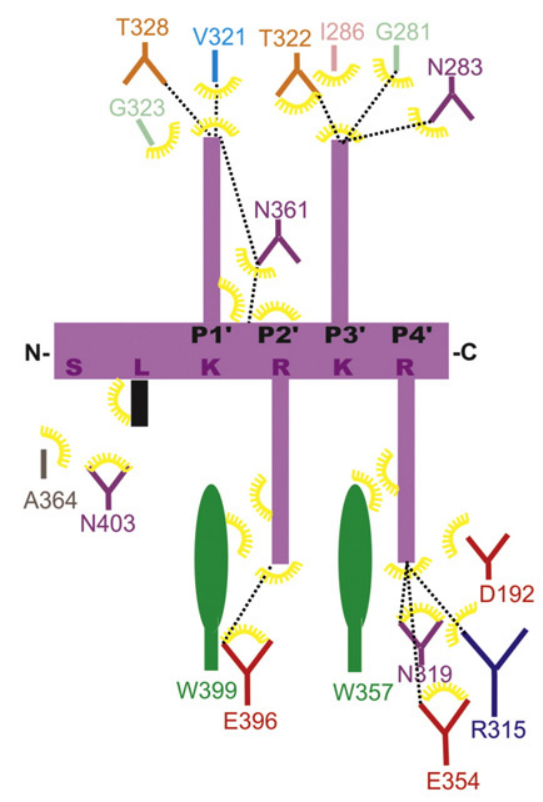

(b) Minor Site

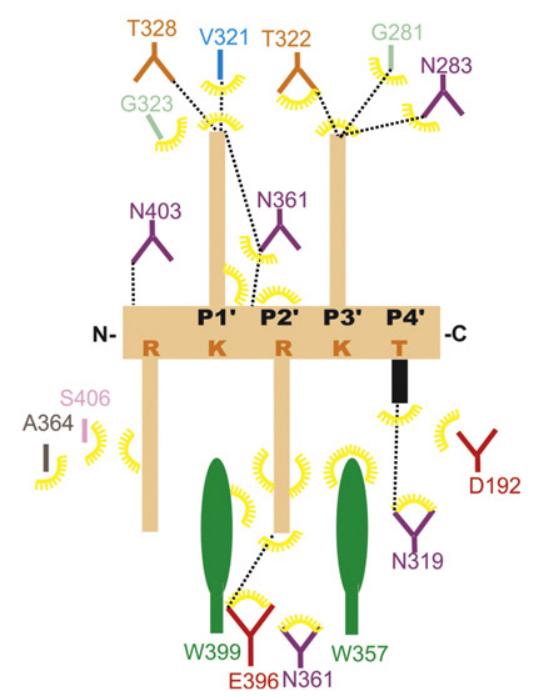

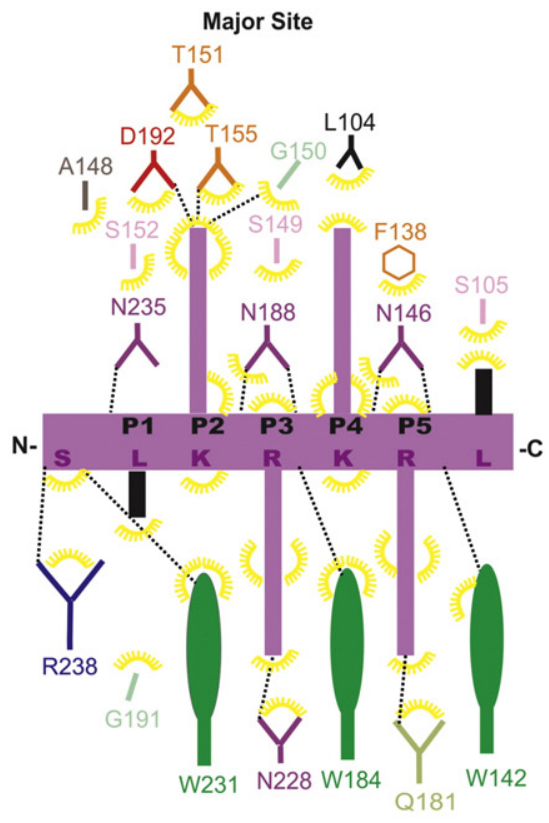

Major Site

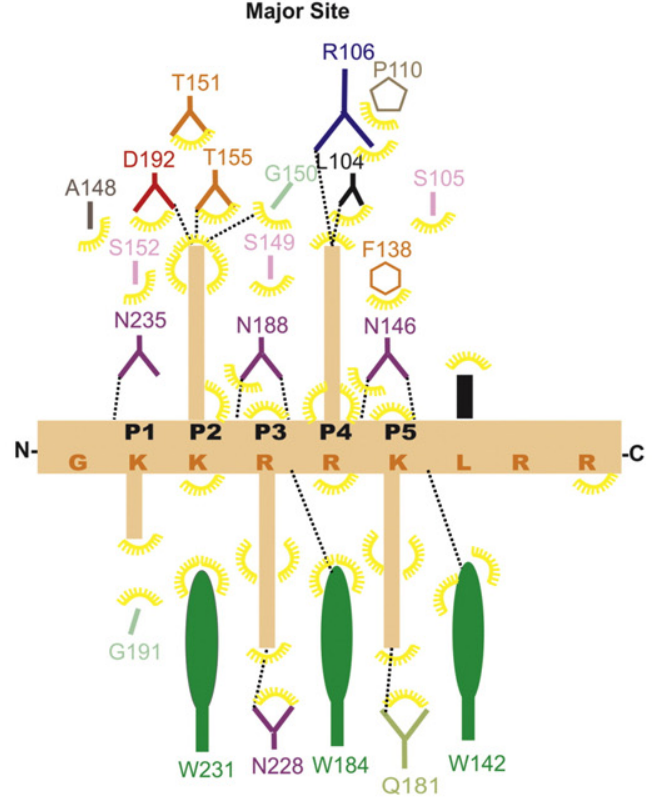

Fig. 4. Schematic diagram of the interactions between the XPG1 and XPG2 NLS peptides and minor and major binding sites of Impa. The peptide backbone is drawn in purple [(a), XPG1 NLS] or in orange [(b), XPG2 NLS] with the residues identified by the one-letter code. Impa side-chain residues interacting with the peptide are indicated with their names and different colors. Polar contacts are shown with broken lines, and hydrophobic contacts are indicated by arcs with radiating spokes.

show that these structures are well conserved, as observed in Fig. 5. Other structural studies also demonstrated the high structural conservation of monopartite NLS peptides [26] when bound to the protein receptor. ITC assays using XPG1 and XPG2 NLS peptides reveal two binding sites of Impa with different affinity values, similar to the monopartite SV40 TAg NLS peptide $[23,24]$. $K_{d}$ values for XPG1, XPG2 or SV40 TAg NLSs binding to the major binding sites of mammalian or Neurospora crassa Impa proteins are of similar magnitude. This fact is consistent with the high conservation of residues in 

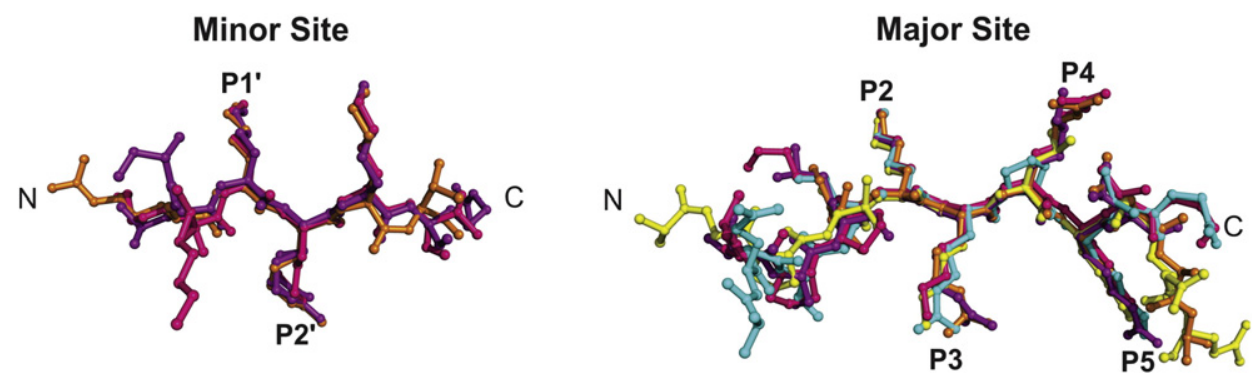

Fig. 5. Comparison of NLS peptides in the minor and major NLS-binding sites. XPG1 (purple), XPG2 (orange), SV40 TAg (pink) [31], Ku70 (cyan) [26] and Ku80 (yellow) [26]. Positions binding to the major (P1-P5) and minor (P1'-P4') binding sites are identified along the chains.

the most important positions of major binding sites, consistent with the consensus sequence (Table 2). Thus, structural and calorimetric data unambiguously show that XPG1 and XPG2 NLS peptides bind to Impa as a classical monopartite NLSs.

At the minor binding site, the XPG2 peptide has a slightly higher RMSD to the SV40 TAg NLS peptide, compared to XPG1, but the residues in the key positions $\mathrm{P} 1^{\prime}-\mathrm{P} 2^{\prime}-\mathrm{P}^{\prime}$ positions are structurally conserved (Fig. 5). However, the analysis of the electron density map of the XPG2 NLS peptide shows some ambiguity, particularly at the $\mathrm{N}$ - and C-termini of the peptide, which could be caused by multiple interaction modes between the peptide and the receptor, peptide staggering and the moderate resolution of the data. This behavior may be due to the presence of several Lys/Arg residues in three different regions of the XPG2 NLS (Table 2), which may enable multiple binding modes. Peptide staggering has been also observed in the minor NLS-binding site of the SV40 TAg NLS structure, which also has a large content of basic residues [21]. The ITC assays performed using XPG2 NLS peptide show lower-affinity values compared to XPG1 NLS (40-fold difference). The structural reasons for this are not entirely clear, but we suggest that it may be related to the multiple binding modes of peptide with the protein receptor. Nuclear localization patterns

Table 2. Binding of monopartite and bipartite NLSs to specific binding pockets of $M$. musculus Impa

\begin{tabular}{|c|c|c|c|c|c|c|c|c|c|c|c|c|c|c|c|c|c|c|c|c|c|c|c|c|c|}
\hline NLSs & & & & & $\mathrm{Mi}$ & nor & & & & & & & & & & & & & & Majo & & & & & \\
\hline Monopartite & & & & $\mathrm{P} 1^{\prime}$ & $\mathrm{P} 2^{\prime}$ & P3' & $P 4^{\prime}$ & & & & & & & & & & & P1 & P2 & P3 & P4 & P5 & & & \\
\hline Ku80 & & & & & & & & & & & & & $E$ & D & $G$ & $\mathrm{P}$ & $\mathrm{T}$ & A & $\mathbf{K}$ & $\mathbf{K}$ & L & $\mathbf{K}$ & $\mathrm{T}$ & $\mathrm{E}$ & \\
\hline Ku70 & & & & $\mathbf{K}$ & V & $\mathrm{T}$ & $\mathrm{K}$ & $\mathrm{R}$ & & $\mathrm{K}$ & $\mathrm{H}$ & D & $\mathrm{N}$ & $E$ & $\mathrm{G}$ & $\mathrm{S}$ & G & $S$ & $\mathbf{K}$ & $\mathbf{R}$ & $\mathbf{P}$ & $\mathbf{K}$ & & & \\
\hline PLSCR1 & & & & & & & & & & & & & & & & & & $\mathrm{G}$ & $\mathbf{K}$ & I & $\mathbf{S}$ & $\mathbf{K}$ & $\mathrm{H}$ & W & \\
\hline $\mathrm{AR}$ & & & & & $\mathrm{R}$ & K & C & $Y$ & & E & A & G & $M$ & $\mathrm{~T}$ & $\mathrm{~L}$ & $\mathrm{G}$ & A & $\mathrm{R}$ & $\mathbf{K}$ & L & $\mathrm{K}$ & $\mathbf{K}$ & $\mathrm{L}$ & G & \\
\hline SV40 & & $P$ & $\mathrm{~K}$ & K & $\mathbf{K}$ & $\mathrm{R}$ & $\mathrm{K}$ & V & & & & & & A & $\bar{A}$ & $\mathrm{P}$ & $P$ & $\mathrm{~K}$ & $\mathbf{K}$ & $\mathbf{K}$ & $\mathbf{R}$ & $\mathbf{K}$ & $\overline{\mathrm{V}}$ & E & \\
\hline CN-SV40 & & & $\mathrm{K}$ & K & $\mathbf{R}$ & $\mathrm{K}$ & V & & & & & & & $\ldots$ & $A$ & $P$ & $\mathrm{P}$ & $\mathrm{K}$ & $\mathbf{K}$ & $\mathbf{K}$ & $\mathbf{R}$ & $\mathbf{K}$ & V & & \\
\hline c-Myc & & & & $\mathbf{K}$ & $\mathbf{R}$ & V & $\mathrm{K}$ & $\mathrm{L}$ & & & & & & & & $\mathrm{P}$ & A & A & $\mathbf{K}$ & $\mathbf{R}$ & V & $\mathbf{K}$ & $\mathrm{L}$ & D & \\
\hline mPet TM & & & $\mathrm{K}$ & $\mathbf{K}$ & $\mathbf{R}$ & $\mathrm{R}$ & E & A & & & & & & & & & & $\mathrm{F}$ & $\mathbf{K}$ & $\mathbf{K}$ & $\mathrm{K}$ & $\mathbf{R}$ & $\mathrm{R}$ & $\mathrm{E}$ & A \\
\hline XPG1 & & $S$ & $\mathrm{~L}$ & $\mathbf{K}$ & $\mathbf{R}$ & $\mathrm{K}$ & $\mathrm{R}$ & & & & & & & & & & $S$ & $\mathrm{~L}$ & $\mathbf{K}$ & $\mathbf{R}$ & $\mathbf{K}$ & $\mathbf{R}$ & & & \\
\hline XPG2 & & & $\mathrm{R}$ & $\mathbf{K}$ & $\mathbf{R}$ & K & $\mathrm{T}$ & & & & & & & & & & $\mathrm{G}$ & $\bar{K}$ & $\mathbf{K}$ & $\mathbf{R}$ & $\mathbf{R}$ & $\mathbf{K}$ & $\mathrm{L}$ & $\mathrm{R}$ & \\
\hline Bipartite & & & & P1' & P2' & P3' & P4' & & & & & Lir & ker & & & & & P1 & P2 & P3 & P4 & P5 & & & \\
\hline FEN-1 & $S$ & $S$ & $A$ & $\mathbf{K}$ & $\mathbf{R}$ & $\mathrm{K}$ & $E$ & & & & $P$ & $E$ & $P$ & $\mathrm{~K}$ & $G$ & $S$ & $\mathrm{~T}$ & $\mathrm{~K}$ & $\mathbf{K}$ & K & A & K & $\mathrm{T}$ & & \\
\hline NP & & $A$ & V & $\mathbf{K}$ & $\mathbf{R}$ & $P$ & $\bar{A}$ & & & & A & $\overline{\mathrm{T}}$ & $\mathrm{K}$ & $\mathrm{K}$ & A & $\mathrm{G}$ & $Q$ & $A$ & $\mathbf{K}$ & K & K & K & $\mathrm{L}$ & & \\
\hline RB & & & & $\mathbf{K}$ & $\mathbf{R}$ & S & A & & & $E$ & $\mathrm{G}$ & S & $\mathrm{N}$ & $\mathrm{P}$ & $\mathrm{P}$ & $\mathrm{K}$ & $\mathrm{P}$ & $\mathrm{L}$ & $\mathbf{K}$ & K & L & $\mathbf{R}$ & $\mathrm{G}$ & & \\
\hline N1N2 & & $\mathrm{R}$ & $\mathrm{K}$ & K & $\mathbf{R}$ & $\mathrm{K}$ & $\mathrm{T}$ & $\mathrm{E}$ & & $\mathrm{E}$ & $\mathrm{E}$ & $S$ & $P$ & L & $\mathrm{K}$ & D & $\mathrm{K}$ & A & $\mathbf{K}$ & $\mathbf{K}$ & $\mathbf{s}$ & $\mathbf{K}$ & $\mathrm{G}$ & & \\
\hline CBP80 & & & $\mathrm{s}$ & $\mathbf{R}$ & $\mathbf{R}$ & $\mathrm{R}$ & $\mathrm{H}$ & $\mathrm{S}$ & & $\bar{D}$ & $\mathrm{E}$ & $\mathrm{N}$ & $\mathrm{D}$ & $\mathrm{G}$ & $\mathrm{G}$ & $Q$ & $\mathrm{P}$ & $\mathrm{H}$ & $\mathbf{K}$ & $\mathbf{R}$ & $\mathbf{R}$ & $\mathbf{K}$ & $\mathrm{T}$ & $\mathrm{S}$ & \\
\hline mCBP80 & & & $M$ & $\mathrm{~S}$ & $\mathbf{R}$ & $\mathrm{R}$ & $\mathrm{R}$ & $\mathrm{H}$ & $\mathrm{S}$ & $\mathrm{Y}$ & $\mathrm{E}$ & $\mathrm{N}$ & $\mathrm{D}$ & $\mathrm{G}$ & $\mathrm{G}$ & $Q$ & $\mathrm{P}$ & $\mathrm{H}$ & $\mathbf{K}$ & $\mathbf{R}$ & $\mathbf{R}$ & $\mathbf{K}$ & $\mathrm{T}$ & $\mathrm{S}$ & \\
\hline yCBP80 & & $\mathrm{N}$ & $\mathrm{R}$ & $\mathbf{K}$ & $\mathbf{R}$ & $\mathrm{R}$ & $\mathrm{G}$ & D & & & DED & EN & YRDF & FRPF & & & $M$ & $P$ & $\mathbf{K}$ & $\mathbf{R}$ & $\mathbf{Q}$ & $\mathbf{R}$ & I & $\mathrm{P}$ & \\
\hline TPX2 & & & & $\mathbf{K}$ & $\mathbf{R}$ & $\mathrm{K}$ & $\mathrm{H}$ & $\ldots$ & & & & & & & & & & V & $\mathbf{K}$ & M & I & K & $\mathrm{L}$ & & \\
\hline Prp20 & & & & $\mathbf{K}$ & $\mathbf{R}$ & $\mathrm{T}$ & V & & & AT & NGD & DAS & $\mathrm{GA}$ & & $\mathrm{H}$ & $\mathrm{R}$ & $A$ & $\mathrm{~K}$ & $\mathbf{K}$ & M & s & K & & & \\
\hline BIMAX1 & & $\mathrm{P}$ & $\mathrm{R}$ & $\mathbf{K}$ & $\mathbf{R}$ & $\mathrm{P}$ & L & & $\mathrm{E}$ & W & D & $\mathrm{E}$ & D & $E$ & $E$ & $\mathrm{P}$ & $P$ & $\mathrm{R}$ & $\mathbf{K}$ & $\mathbf{R}$ & $\mathrm{K}$ & $\mathbf{R}$ & $\mathrm{L}$ & W & \\
\hline BIMAX2 & $\mathrm{R}$ & $\mathrm{R}$ & $\mathrm{R}$ & K & $\mathbf{R}$ & $\mathrm{K}$ & $\mathrm{R}$ & & $\mathrm{E}$ & W & D & D & D & D & D & $\mathrm{P}$ & $\mathrm{P}$ & $\mathrm{K}$ & K & $\mathbf{R}$ & $\mathbf{R}$ & $\mathbf{R}$ & $\mathrm{L}$ & D & \\
\hline Consensus & & & & $\mathbf{K}$ & $\mathbf{R}$ & & & & & 10 & $12 \mathrm{re}$ & & lues & & & & & & $\mathbf{K}$ & $\mathrm{R} / \mathrm{K}$ & $x$ & $\mathrm{R} / \mathrm{K}$ & & & \\
\hline
\end{tabular}



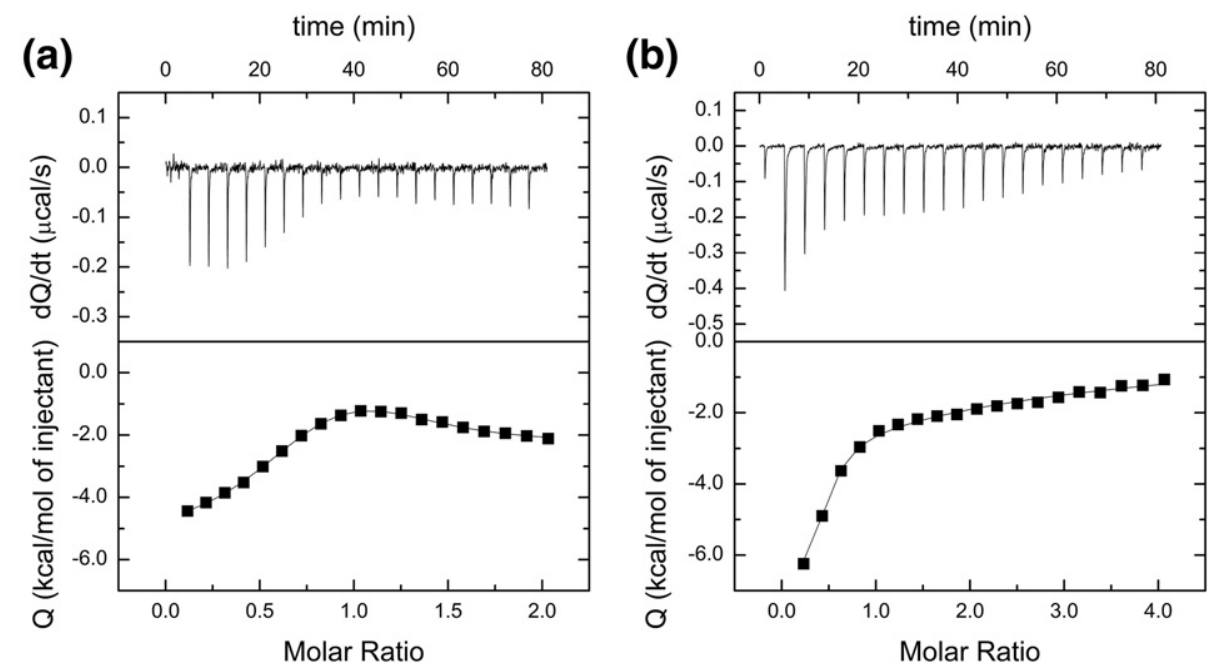

Fig. 6. Calorimetric titration of XPG1 and XPG2 NLS peptides into Impa. The upper panel shows the raw data thermogram (thermal power as a function of time) of the titration of Impa with (a) XPG1 and (b) XPG2 NLSs. The lower panel shows the binding isotherm (ligand-normalized integrated heat as a function of the molar ratio). Affinities and enthalpy changes were determined by a general non-linear regression model considering two ligand binding sites (continuous line).

differ between XPG1 and XPG2 [13], which may be caused by the binding differences between the NLS peptides.

\section{Why XPG1 and XPG2 NLS peptides do not bind to Impa as classic bipartite NLSs?}

Candidates for NLS in the XPG protein have been tested using in situ immunofluorescence localization of transiently expressed $\beta$-galactosidase fusion proteins [12]. The authors of the study proposed two peptides from the C-terminal region of XPG: NLS-B or XPG1 $\left({ }^{1057}\right.$ KRGITNTLEESSSLKRKRL $\left.{ }^{1074}\right)$ and NLS-C or XPG2 $\left({ }^{1169}\right.$ GKKRRKLRRARGRKRKT $\left.{ }^{1186}\right)$ as putative bipartite NLSs. This conclusion is partially supported by the analysis using the PSORT program [32], which predicts only the XPG1 sequence as a probable bipartite NLS. Surprisingly, our structural results clearly show that both peptides are bound to the Impa receptor as classic monopartite NLSs. Furthermore, ITC results for XPG1 and XPG2 NLSs demonstrate that the ligands bind to the receptor at two sites with different

Table 3. Thermodynamic parameters for binding of XPG1 and XPG2 NLSs to Impa

\begin{tabular}{lllc}
\hline & & \multicolumn{1}{c}{$\begin{array}{c}\text { Major } \\
\text { binding site }\end{array}$} & $\begin{array}{c}\text { Minor } \\
\text { binding site }\end{array}$ \\
\hline Impa-XPG1 NLS & $K_{d}(\mu \mathrm{M})$ & $0.45 \pm 0.05$ & $3.4 \pm 0.5$ \\
& $\Delta H(\mathrm{kcal} / \mathrm{mol})$ & $-3.2 \pm 0.3$ & $3.8 \pm 0.3$ \\
& $-T \Delta S(\mathrm{cal} / \mathrm{mol} / \mathrm{deg})$ & $-5.3 \pm 0.3$ & $11.1 \pm 0.1$ \\
Impa-XPG2 NLS & $K_{\mathrm{d}}(\mu \mathrm{M})$ & $0.91 \pm 0.09$ & $140 \pm 20$ \\
& $\Delta H(\mathrm{kcal} / \mathrm{mol})$ & $-6.9 \pm 0.8$ & $-21 \pm 1$ \\
& $-T \Delta S(\mathrm{cal} / \mathrm{mol} / \mathrm{deg})$ & $-1.2 \pm 0.8$ & $16 \pm 1$ \\
\hline
\end{tabular}

affinities, similarly to the classical monopartite NLS SV40 TAg, supporting the structural results [24].

Taking into account that the current consensus sequence for a classical bipartite NLS is $\mathrm{KRX}_{10-12} \mathbf{K}(\mathrm{K} / \mathrm{R}) \mathrm{X}(\mathrm{K} / \mathrm{R})[27,31,33]$, it is possible to conclude that the XPG2 sequence does not match the consensus sequence for bipartite NLSs because a Lys residue should be present in the position $\mathrm{P} 1^{\prime}$ and an Arg residue should be present in the position P2' with a minimum of 10 residues in the linker region [31] (Table 2). On the other hand, XPG1 matches all requirements for a classical bipartite NLS; however, the structural data obtained here indicate that the C-terminal basic cluster (KRKR) of the peptide has a higher affinity for the minor site than its $\mathrm{N}$-terminal basic cluster (KR).

It has been suggested that the positions preceding the $\mathrm{P} 1^{\prime}$ and following $\mathrm{P} 2$ ' contribute significantly to the binding with the minor site $[16,19,31]$. Additionally, the content of acidic, proline and hydrophobic residues in the linker region also has a role in the stabilization of bipartite NLS peptides [17,19,34,35]. It can be observed in the Impa-XPG1 NLS structure that P3' and $\mathrm{P}^{\prime}$ ' positions are often occupied with, respectively, Lys and Arg residues (Table 2). The Lys side chain at the $\mathrm{P}^{\prime}$ ' position interacts to N283, T322 and G381 by hydrogen bonds and with other residues by hydrophobic contacts (Fig. 4). These interactions would not occur if the peptide bound to Impa as a bipartite NLS because a Gly residue would be in the P3' position (Table 2). Similarly, the Arg side chain at the P4' position is hydrogen-bonded to E354, R315 and N319 (Fig. 4). These interactions would be not possible if the lle residue would be in this position for a supposed bipartite interaction of the XPG1 peptide. 
Furthermore, the putative linker region of the XPG1 peptide presents several uncharged polar residues and just two polar residues. These residues do not present favorable interactions with Impa according to previous studies $[19,35]$. It has also been observed that the 12-residue length for linker region, as for XPG1 NLS, is less favorable compared to the 11-residue length or the 10-residue length [27].

It can be noted from Table 2 that the majority of bipartite NLS sequences bound to Impa present Lys/ Arg residues in the $\mathrm{P}^{\prime}$ position and it was observed that monopartite NLS peptides that only bind to major binding site do not contain three sequential Lys/Arg residues; their binding to the minor binding site is therefore not favored (Table 2). These observations point to the importance of Lys/Arg residues at the $\mathrm{P}^{\prime}$ for minor site binding. Similar features are observed in the P3 position (major NLS-binding site), where the side chain of a basic residue is hydrogen-bonded to Asn of Impa and it is not a mandatory residue for peptide binding but strengthens its affinity (e.g., TPX2 and Prp20 peptides do not contain basic residues in the P3 position; Table 2).

\section{What is the role of XPG1 and XPG2 sequences in the XPG protein?}

$\mathrm{XPG}$ is a protein with a molecular mass of $134 \mathrm{kDa}$ (1186-amino-acid residues for human XPG) that needs to be actively translocated to the cell nucleus to promote DNA repair by NER. It has been experimentally demonstrated that NLSs are responsible for the delivery of XPG into the nucleus [12] and that a $\beta$-galactosidase fusion protein containing the C-terminal region of the XPG protein (residues 1146-1185) localizes to the nucleus after UV irradiation [6]. These authors [6] also observed that the XPG protein is retained within the nucleus by a tight, but reversible, association with nuclear structures and its distribution in the nucleus may regulate relative NER rates in the transcriptionally active and inactive nuclear compartments. Indeed, as previously discussed here, localization of transiently expressed $\beta$-galactosidase fusion proteins identified two putative bipartite cNLSs in the same C-terminal region [6].

In the light of structural and calorimetric studies presented here and the functional studies with the C-terminal region of XPG protein $[6,13]$, some questions arise:

- Are the two adjacent NLS sequences required to translocate the XPG protein?

Because only one is sufficient for nuclear translocation, and taking into account the affinity measurements presented here (2-fold lower affinity for the major
NLS-binding site and 40-fold lower affinity for minor NLS-binding site for XPG2 compared to XPG1), it is likely that only the XPG1 sequence is the NLS responsible for the translocation of the XPG protein to the nucleus.

- Is the XPG protein translocated to the nucleus via a monopartite or bipartite NLS process?

The results presented here unambiguously demonstrate that the NLS peptide binds to Impa as a monopartite NLS. However, the binding of full-length XPG to Impa may be more complex. It is likely that the main basic cluster identified in this work (KRKR) only binds to the major binding site due to steric hindrance; thus, the minor binding site would be empty and available for eventual binding of $\mathrm{KR}$ residues to $\mathrm{P}^{\prime}{ }^{\prime}$ and $\mathrm{P} 2$ ' binding pockets. However, as discussed here, due to the relative low affinity of this region of NLS to the receptor, this is not a mandatory event for the translocation process of the XPG protein and an eventual mutation in these residues will not affect significantly the nuclear import process. Thus, the monopartite NLS binding is the major event for the XPG dockage to Impa.

- What is the role for XPG2 sequence in the XPG protein?

Park and colleagues [6] suggested XPG2 as a putative NRS [22], based on functional experiments. Our affinity experiments demonstrated the lower affinity for this peptide fragment to NLS-binding regions to both binding sites of Impa. However, this sequence is a suitable candidate for an NRS.

In conclusion, based on crystallographic and calorimetric assays, we demonstrate that a C-terminal region previously proposed to be a potential NLS sequence of the XPG protein (XPG1 fragment) is able to bind with high affinity to Impa receptor as a classical monopartite NLS sequence. By contrast, the other C-terminal basic cluster (XPG2), previously also proposed to be an NLS, binds to Impa with lower affinity and possibly using multiple binding modes. This latter sequence may therefore function instead as an NRS, rather than NLS.

\section{Materials and Methods}

\section{Synthesis of NLS peptides}

The peptides corresponding to XPG1 NLS $\left({ }^{1054}\right.$ KTQKRGITNTLEESSSLKRKRLSD $\left.{ }^{1076}\right)$ and XPG2 NLS $\left({ }^{1166}\right.$ VFGKKRRKLRRARGRKRKT $\left.{ }^{1186}\right)$ were synthesized by Proteimax (Brazil) with purity higher than $99 \%$. The peptides have additional residues at the $\mathrm{N}$ - and 
C-termini to the minimal identified NLS [36] to avoid artifactual binding at the termini [21].

\section{Protein expression and purification}

Hexa-His-tagged truncated M. musculus Impa2, comprising amino acids 70-529 (Impa $\Delta$ IBB), was expressed and purified by nickel affinity chromatography as described previously [37]. The protein was eluted using a gradient of imidazole followed by dialysis. The Impa sample was stored in a buffer composed of $20 \mathrm{mM}$ Tris$\mathrm{HCl}(\mathrm{pH}$ 8.0), $100 \mathrm{mM}$ sodium chloride and $10 \mathrm{mM}$ DTT at $-20{ }^{\circ} \mathrm{C}$. The purity was estimated to be $98 \%$ by SDS-PAGE.

\section{Calorimetric assays}

ITC assays were used to quantify the binding of XPG1 and XPG2 NLS peptides and Impa $\triangle \mathrm{IBB}$. ITC measurements were performed using a MicroCal iTC200 microcalorimeter (GE Healthcare) calibrated according to the manufacturer's instructions. All samples were dialyzed against the ITC buffer $[20 \mathrm{mM}$ Tris- $\mathrm{HCl}(\mathrm{pH} 8.0)$ and $100 \mathrm{mM}$ sodium chloride] and degassed before titration. The sample cell was loaded with $30 \mu \mathrm{M}(200 \mu \mathrm{l})$ of Impa $\triangle \mathrm{IBB}$ that was individually titrated with the NLS peptides at a concentration of $300 \mu \mathrm{M}$ XPG1 and $450 \mu \mathrm{M}$ XPG2. Titrations were performed at $20{ }^{\circ} \mathrm{C}$ with 20 injections, first containing $0.4 \mu \mathrm{l}$ (excluded from data analysis) and the following containing $2 \mu \mathrm{l}$ with an interval of $240 \mathrm{~s}$ with an 800-rpm homogenization speed. Heats of dilution and mixing were measured by titration with XPG1 or XPG2 NLSs into the ITC buffer and the values were subtracted for data analyses. Data were analyzed with binding polynomials $[38,39]$.

\section{Crystallization and crystal structure determination}

Impa $\triangle \mathrm{IBB}$ was concentrated to $18 \mathrm{mg} / \mathrm{ml}$ using a Vivaspin 20, $30 \mathrm{kDa}$ (GE Healthcare) and stored at $-20{ }^{\circ} \mathrm{C}$. Crystallization conditions were screened by systematically altering various parameters using, as a starting point, the crystallization conditions that had been successful for other peptide complexes [21,27]. The crystals were obtained using co-crystallization, by combining $1 \mu \mathrm{l}$ of protein solution, $0.5 \mu \mathrm{l}$ of peptide solution (peptide/protein molar ratio of 4 for XPG1 and of 8 to XPG2 peptides) and $1 \mu \mathrm{l}$ of reservoir solution on a coverslip and suspending the mixture over $0.5 \mathrm{ml}$ of reservoir solution. Single crystals were obtained with a reservoir solution containing $0.6-0.7 \mathrm{M}$ sodium citrate $(\mathrm{pH} 6)$ and $10 \mathrm{mM}$ DTT after 15-20 days.

X-ray diffraction data were collected from a single NLS crystal at the National Synchrotron Light Source, Upton, New York, with a Pilatus 6M detector at the beamline X25. For the Impa-XPG2 complex, X-ray diffraction data were also collected from a single crystal at Laboratório Nacional de Luz Síncrotron, Campinas, Brazil, with a MarMosaic 225 detector (MAR Research) at the beamline MX-2. Crystals were mounted in nylon loops, transiently soaked in a reservoir solution supplemented with $25 \%$ glycerol and flash-cooled at $100 \mathrm{~K}$ in a nitrogen stream (Oxford
Nitrogen Cryojet XL, Oxford Cryosystems). Data were processed using the HKL2000 package [40]. Crystals have the symmetry of the $P 2_{1} 2_{1} 2_{1}$ space group and are isomorphous to other mammalian Impa $\triangle I B B-N L S$ peptide complexes (Table 1). The structure of the complex with CN-SV40 TAg NLS (PDB ID 1Q1S [31]), with the NLSs peptides omitted, was employed as the starting model for crystallographic refinement. Refmac5 [41] and PHENIX [42] programs were used to refine the structures and the Coot [43] program for manual modeling. The final models consist of 424 residues of Impa $\Delta$ IBB for both complexes and of 185 and 2 water molecules, respectively, for Impa-XPG1 NLS and Impa-XPG2 NLS structures. For both complexes, fragments of the NLS peptides were found in the minor and major binding sites of the protein (residues 1069-1075 and 1069-1173 in the major binding site and residues 10691074 and $1182-1186$ in the minor binding site, respectively, for Impa-XPG1 NLS and Impa-XPG2 NLS). Structure quality was checked with the program PROCHECK [44] and the contacts were analyzed by the program LIGPLOT [45] (Table 1).

\section{PDB accession codes}

Coordinates and structure factors from both structures have been deposited in the PDB under accession codes $5 E K F$ (XPG1-NLS:m Impa $\triangle \mathrm{IBB})$ and $5 \mathrm{EKG}$ (XPG2-NLS:mlmpa $\triangle \mathrm{IBB}$ ).

\section{Acknowledgements}

This work was supported by FAPESP (Fundação de Amparo à Pesquisa do Estado de São Paulo, Brazil), CNPq (Conselho Nacional de Desenvolvimento Científico e Tecnológico, Brazil) and Spanish Ministerio de Economía y Competitividad (BFU2013-47064-P to A.V.C.). B.K. is an NHMRC (National Health and Medical Research Council) Research Fellow (1003325), A.A.S.T. is a CAPES (Coordenação de Aperfeiçoamento de Pessoal de Nível Superior) Research Fellow and M.R.M.F. is a CNPq Research Fellow. We acknowledge the use of the Laboratório Nacional de Luz Síncrotron (Brazil) and National Synchrotron Light Source (New York, USA).

Received 17 November 2015; Received in revised form 8 January 2016; Accepted 14 January 2016 Available online 23 January 2016

Keywords: importin-a;

xeroderma pigmentosum protein; nuclear localization sequence (NLS);

DNA repair proteins; nucleotide excision repair; 


\begin{abstract}
Abbreviations used:
XPG, xeroderma pigmentosum type G; NER, nucleotide excision repair; NLS, nuclear localization signal; ITC, isothermal titration calorimetry; cNLS, classical nuclear localization sequence; NRS, nuclear retention signal; Impa, importin- $\alpha$.
\end{abstract}

\section{References}

[1] O.D. Scharer, Nucleotide excision repair in eukaryotes, Cold Spring Harb. Perspect. Biol. 5 (2013) a012609.

[2] L.C. Gillet, O.D. Scharer, Molecular mechanisms of mammalian global genome nucleotide excision repair, Chem. Rev. 106 (2006) 253-276.

[3] S.M. Shell, Y. Zou, Other proteins interacting with XP proteins, Adv. Exp. Med. Biol. 637 (2008) 103-112.

[4] O.D. Scharer, XPG: Its products and biological roles, Adv. Exp. Med. Biol. 637 (2008) 83-92.

[5] M. Wakasugi, J.T. Reardon, A. Sancar, The non-catalytic function of XPG protein during dual incision in human nucleotide excision repair, J. Biol. Chem. 272 (1997) 16030-16034.

[6] M.S. Park, J.A. Knauf, S.H. Pendergrass, C.H. Coulon, G.F. Strniste, B.L. Marrone, et al., Ultraviolet-induced movement of the human DNA repair protein, Xeroderma pigmentosum type G, in the nucleus, Proc. Natl. Acad. Sci. USA. 93 (1996) 8368-8373.

[7] S.J. Araujo, R.D. Wood, Protein complexes in nucleotide excision repair, Mutat. Res. 435 (1999) 23-33.

[8] B.C. Feltes, D. Bonatto, Overview of xeroderma pigmentosum proteins architecture, mutations and post-translational modifications, Mutat. Res. Rev. Mutat. Res. 763 (2015) 306-320.

[9] S. Emmert, H. Slor, D.B. Busch, S. Batko, R.B. Albert, D. Coleman, et al., Relationship of neurologic degeneration to genotype in three xeroderma pigmentosum group $\mathrm{G}$ patients, J. Investig. Dermatol. 118 (2002) 972-982.

[10] T. Narita, K. Narita, A. Takedachi, M. Saijo, K. Tanaka, Regulation of transcription elongation by the XPG-TFIIH complex is implicated in Cockayne syndrome, Mol. Cell. Biol. 35 (2015) 3178-3188.

[11] M. Hohl, I. Dunand-Sauthier, L. Staresincic, P. JaquierGubler, F. Thorel, M. Modesti, et al., Domain swapping between FEN-1 and XPG defines regions in XPG that mediate nucleotide excision repair activity and substrate specificity, Nucleic Acids Res. 35 (2007) 3053-3063.

[12] J.A. Knauf, S.H. Pendergrass, B.L. Marrone, G.F. Strniste, M.A. Maclnnes, M.S. Park, Multiple nuclear localization signals in XPG nuclease, Mutat. Res. 363 (1996) 67-75.

[13] A. Constantinou, D. Gunz, E. Evans, P. Lalle, P.A. Bates, R.D. Wood, et al., Conserved residues of human XPG protein important for nuclease activity and function in nucleotide excision repair, J. Biol. Chem. 274 (1999) 5637-5648.

[14] T.W. Kirby, N.R. Gassman, C.E. Smith, L.C. Pedersen, S.A. Gabel, M. Sobhany, et al., Nuclear localization of the DNA repair scaffold XRCC1: Uncovering the functional role of a bipartite NLS, Sci. Rep. Uk. 5 (2015).

[15] A. Lange, R.E. Mills, C.J. Lange, M. Stewart, S.E. Devine, A.H. Corbett, Classical nuclear localization signals: Definition, function, and interaction with importin alpha, J. Biol. Chem. 282 (2007) 5101-5105.
[16] C.W. Chang, R.M. Counago, S.J. Williams, M. Boden, B. Kobe, Distinctive conformation of minor site-specific nuclear localization signals bound to importin-alpha, Traffic 14 (2013) 1144-1154.

[17] A.C. de Barros, A.A.S. Takeda, C.W. Chang, B. Kobe, M.R.M. Fontes, Structural basis of nuclear import of flap endonuclease 1 (FEN1), Acta Crystallogr. D Biol. Crystallogr. 68 (2012) 743-750.

[18] M. Rexach, G. Blobel, Protein import into nuclei-Association and dissociation reactions involving transport substrate, transport factors, and nucleoporins, Cell 83 (1995) 683-692.

[19] M. Marfori, T.G. Lonhienne, J.K. Forwood, B. Kobe, Structural basis of high-affinity nuclear localization signal interactions with importin-alpha, Traffic 13 (2012) 532-548.

[20] M. Marfori, A. Mynott, J.J. Ellis, A.M. Mehdi, N.F. Saunders, P.M. Curmi, et al., Molecular basis for specificity of nuclear import and prediction of nuclear localization, Biochim. Biophys. Acta 2011 (1813) 1562-1577.

[21] M.R. Fontes, T. Teh, B. Kobe, Structural basis of recognition of monopartite and bipartite nuclear localization sequences by mammalian importin-alpha, J. Mol. Biol. 297 (2000) 1183-1194.

[22] M.S. Schmidt-Zachmann, C. Dargemont, L.C. Kuhn, E.A. Nigg, Nuclear export of proteins: The role of nuclear retention, Cell 74 (1993) 493-504.

[23] N.E. Bernardes, A.A. Takeda, T.R. Dreyer, F.Z. Freitas, M.C. Bertolini, M.R. Fontes, Structure of importin-alpha from a filamentous fungus in complex with a classical nuclear localization signal, PLoS ONE 10 (2015) e0128687.

[24] M.L. Cutress, H.C. Whitaker, I.G. Mills, M. Stewart, D.E. Neal, Structural basis for the nuclear import of the human androgen receptor, J. Cell Sci. 121 (2008) 957-968.

[25] B. Kobe, Autoinhibition by an internal nuclear localization signal revealed by the crystal structure of mammalian importin alpha, Nat. Struct. Biol. 6 (1999) 388-397.

[26] A.A.S. Takeda, A.C. de Barros, C.W. Chang, B. Kobe, M.R.M. Fontes, Structural basis of importin-alpha-mediated nuclear transport for Ku70 and Ku80, J. Mol. Biol. 412 (2011) 226-234.

[27] M.R. Fontes, T. Teh, D. Jans, R.I. Brinkworth, B. Kobe, Structural basis for the specificity of bipartite nuclear localization sequence binding by importin-alpha, J. Biol. Chem. 278 (2003) 27981-27987.

[28] E. Conti, M. Uy, L. Leighton, G. Blobel, J. Kuriyan, Crystallographic analysis of the recognition of a nuclear localization signal by the nuclear import factor karyopherin alpha, Cell 94 (1998) 193-204.

[29] C.W. Chang, R.L. Counago, S.J. Williams, M. Boden, B. Kobe, Crystal structure of rice importin-alpha and structural basis of its interaction with plant-specific nuclear localization signals, Plant Cell 24 (2012) 5074-5088.

[30] R.A. Pumroy, G. Cingolani, Diversification of importin-alpha isoforms in cellular trafficking and disease states, Biochem. J. 466 (2015) 13-28.

[31] M.R.M. Fontes, T. Teh, G. Toth, A. John, I. Pavo, D.A. Jans, et al., Role of flanking sequences and phosphorylation in the recognition of the simian-virus-40 large T-antigen nuclear localization sequences by importin-alpha, Biochem. J. 375 (2003) 339-349.

[32] K. Nakai, P. Horton, PSORT: A program for detecting sorting signals in proteins and predicting their subcellular localization, Trends Biochem. Sci. 24 (1999) 34-36.

[33] D. Chelsky, R. Ralph, G. Jonak, Sequence requirements for synthetic peptide-mediated translocation to the nucleus, Mol. Cell. Biol. 9 (1989) 2487-2492. 
[34] S. Kosugi, M. Hasebe, T. Entani, S. Takayama, M. Tomita, H. Yanagawa, Design of peptide inhibitors for the importin alpha/beta nuclear import pathway by activity-based profiling, Chem. Biol. 15 (2008) 940-949.

[35] S. Kosugi, M. Hasebe, N. Matsumura, H. Takashima, E. Miyamoto-Sato, M. Tomita, et al., Six classes of nuclear localization signals specific to different binding grooves of importin alpha, J. Biol. Chem. 284 (2009) 478-485.

[36] N.O. Knudsen, S.D. Andersen, A. Lutzen, F.C. Nielsen, L.J. Rasmussen, Nuclear translocation contributes to regulation of DNA excision repair activities, DNA Repair (Amst) 8 (2009) 682-689.

[37] T. Teh, T. Tiganis, B. Kobe, Crystallization of importin alpha, the nuclear-import receptor, Acta Crystallogr. D Biol. Crystallogr. 55 (1999) 561-563.

[38] S. Vega, O. Abian, A. Velazquez-Campoy, A unified framework based on the binding polynomial for characterizing biological systems by isothermal titration calorimetry, Methods 76 (2015) 99-115.

[39] E. Freire, A. Schon, A. Velazquez-Campoy, Isothermal titration calorimetry: General formalism using binding polynomials, Methods Enzymol. 455 (2009) 127-155.

[40] Z. Otwinowski, Processing of X-ray diffraction data collected in oscillation mode, Methods Enzymol. 276 (1997) 307-326.

[41] G.N. Murshudov, A.A. Vagin, E.J. Dodson, Refinement of macromolecular structures by the maximum-likelihood method, Acta Crystallogr. D Biol. Crystallogr. 53 (1997) 240-255.

[42] P.D. Adams, R.W. Grosse-Kunstleve, L.W. Hung, T.R. loerger, A.J. McCoy, N.W. Moriarty, et al., PHENIX: Building new software for automated crystallographic structure determination, Acta Crystallogr. D Biol. Crystallogr. 58 (2002) 1948-1954.
[43] P. Emsley, K. Cowtan, Coot: Model-building tools for molecular graphics, Acta Crystallogr. D Biol. Crystallogr. 60 (2004) 2126-2132.

[44] R.A. Laskowski, J.A. Rullmannn, M.W. MacArthur, R. Kaptein, J.M. Thornton, AQUA and PROCHECK-NMR: Programs for checking the quality of protein structures solved by NMR, J. Biomol. NMR 8 (1996) 477-486.

[45] A.C. Wallace, R.A. Laskowski, J.M. Thornton, LIGPLOT—A program to generate schematic diagrams of protein ligand interactions, Protein Eng. 8 (1995) 127-134.

[46] M.H. Chen, I. Ben-Efraim, G. Mitrousis, N. Walker-Kopp, P.J. Sims, G. Cingolani, Phospholipid scramblase 1 contains a nonclassical nuclear localization signal with unique binding site in importin alpha, J. Biol. Chem. 280 (2005) 10599-10606.

[47] E. Conti, J. Kuriyan, Crystallographic analysis of the specific yet versatile recognition of distinct nuclear localization signals by karyopherin alpha, Structure 8 (2000) 329-338.

[48] S.N. Yang, A.A. Takeda, M.R. Fontes, J.M. Harris, D.A. Jans, B. Kobe, Probing the specificity of binding to the major nuclear localization sequence-binding site of importin-alpha using oriented peptide library screening, J. Biol. Chem. 285 (2010) 19935-19946.

[49] S.M. Dias, K.F. Wilson, K.S. Rojas, A.L. Ambrosio, R.A. Cerione, The molecular basis for the regulation of the cap-binding complex by the importins, Nat. Struct. Mol. Biol. 16 (2009) 930-937.

[50] A. Giesecke, M. Stewart, Novel binding of the mitotic regulator TPX2 (target protein for Xenopus kinesin-like protein 2) to importin-alpha, J. Biol. Chem. 285 (2010) 17628-17635.

[51] N. Roman, M. Christie, C.M. Swarbrick, B. Kobe, J.K. Forwood, Structural characterisation of the nuclear import receptor importin alpha in complex with the bipartite NLS of Prp20, PLoS ONE 8 (2013) e82038. 